\title{
Dez anos visualizados em uma marca cambiante
}

\author{
Visualizing ten years in a dynamic brand
}

Julia Ebel, Júlia Giannella, Doris Kosminsky, Claudio Esperança

visualização de dados, identidade visual, marca cambiante, logotipo

O presente artigo discute o desenvolvimento de uma marca cambiante utilizando princípios da visualização de dados sob a ótica do Design da Informação. O trabalho foi desenvolvido no âmbito do Laboratório de Visualidade e Visualização (LabVis) da Escola de Belas Artes da Universidade Federal do Rio de Janeiro (EBA-UFRJ), e, por meio de abordagem teórico-prática, visa aprofundar o conhecimento no campo interdisciplinar da visualização de dados. Em decorrência dos dez anos de existência do LabVis, criamos uma marca cambiante que homenageia, simultaneamente, a trajetória e a área de atuação do LabVis. Por meio deste documento, buscamos discorrer sobre o processo de conceituação, pesquisa de semelhantes, execução e aplicação da nova marca.

data visualization, visual identity, changing brand, logo

This paper discusses the development of a generative brand using data visualization principles from the perspective of Information Design. The work was developed within the scope of the Visualization Laboratory (LabVis) of the School of Fine Arts of Federal University of Rio de Janeiro, which, through a theoretical-practical approach, aims to deepen the interdisciplinary field of data visualization. As a result of the 10th anniversary of the Laboratory, we created a generative brand that pays homage to LabVis' trajectory and area of activity. Through this document, we seek to discuss the process of conception, benchmarking, development and application of the new brand.

\section{Introdução}

O Laboratório da Visualidade e Visualização da Universidade Federal do Rio de Janeiro (LabVis-UFRJ) foi criado em 2010 e realiza extenso trabalho de pesquisa e desenvolvimento nas áreas de Design da Informação e visualização de dados, unindo, de forma interdisciplinar, discentes e docentes da graduação e pós-graduação da Escola de Belas Artes e do Instituto Alberto Luiz Coimbra de Pós-Graduação e Pesquisa de Engenharia (COPPE) da UFRJ.

Diante dos desafios trazidos pelo contínuo avanço na produção e no consumo de dados e informações, o LabVis propõe um enfoque metodológico baseado na pesquisa em design a partir da prática, no qual se articulam, de forma rizomática, conceitos e espaços de diversas instâncias investigativas. Dentro desse contexto, o laboratório já conduziu diversos projetos teórico-práticos sobre visualizações de dados científicos e sociais do Brasil.

Em 2020, o LabVis completou sua primeira década de existência e, para celebrar essa data, seus integrantes se viram motivados a criar uma marca comemorativa que refletisse essa

Anais do $10^{\circ} \mathrm{CIDI}$ e $10^{\circ} \mathrm{CONGIC}$

Kelli C.A.S. Smythe, Rafael de Castro Andrade (orgs.)

Sociedade Brasileira de Design da Informação - SBDI

Curitiba | Brasil | 2021
Proceedings of the $10^{\text {th }} \mathrm{CIDI}$ and $10^{\text {th }}$ CONGIC

Kelli C.A.S. Smythe, Rafael de Castro Andrade (orgs.)

Sociedade Brasileira de Design da Informação - SBDI Curitiba | Brazil | 2021 
retrospectiva. Mas como aliar o desafio projetual aos interesses investigativos do Laboratório? Nos tópicos que se seguem, detalhamos o processo de conceituação, pesquisa de semelhantes, execução e aplicação da nova marca do LabVis expondo como esse processo evidencia aspectos do Design da Informação relacionados à visualização de dados e ao processo comunicacional.

\section{Conceituação}

$\mathrm{Na}$ etapa de conceituação, definimos que a questão norteadora do projeto seria criar uma nova marca que fosse, para além de um selo comemorativo, uma visualização de dados em si.

A visualização de dados trata de representações visuais, geralmente interativas e criadas com o uso de computador, com o objetivo de ampliar a cognição e favorecer a aquisição de conhecimentos (Card et al., 1999). Trata-se de uma área de estudo interdisciplinar, essencial diante dos desafios trazidos pelo contínuo avanço na produção e consumo de dados e informações, e na qual as contribuições do design da informação são fundamentais para "... satisfazer as necessidades informacionais dos destinatários pretendidos e de promover eficiência comunicativa" (SBDI, 2020). Mas como a visualização de dados pode ser aplicada na concepção de marcas?

$\mathrm{Na}$ busca de uma solução, chegamos à ideia de conceber um novo logotipo para o LabVis segundo uma lógica de identidade dinâmica, isto é, um sistema visual cuja variabilidade dos elementos constitutivos é responsável pela flexibilidade e mutabilidade da marca (Van Nes, 2012, apud Souza, 2013). A esse tipo específico de manifestação, chamaremos de marca cambiante ${ }^{1}$.

Van Nes (2012) classifica as identidades dinâmicas em seis categorias: Container, Wallpaper, DNA, Fórmula, Customizado e Generativo. A última categoria, generativa, caracteriza marcas que têm sua cambialidade definida por dados automaticamente calculados e processados por um programa de computador ou algoritmo. Em última análise, é na categoria generativa que podemos falar de uma aproximação entre visualização de dados e identidade visual da marca.

A partir dessa conceituação inicial, traçamos dois objetivos projetuais:

1. criar uma marca cambiante que homenageie, simultaneamente, a trajetória e a área de pesquisa do LabVis;

2. compartilhar a nova marca cambiante com o público a partir de sua aplicação em uma série de publicações em redes sociais.

\section{Pesquisa de semelhantes}

Em seguida, realizamos uma pesquisa de semelhantes. Neste artigo, são explicitadas duas importantes referências.

\footnotetext{
${ }^{1} \mathrm{Na}$ literatura, encontramos referência às expressões "marca cambiante", "logotipo cambiante", "logotipo generativo" e "marca generativa". Tratamos essas expressões indistintamente.
} 


\section{EuroVision 2020}

EuroVision é um festival musical europeu que ocorre anualmente desde 1956. Para a edição de 2020, a agência de Design CLEVER ${ }^{\circ}$ FRANKE (2020) concebeu uma marca cambiante que é uma representação abstrata das bandeiras dos países participantes do festival. Na "marcamãe", cada fatia identifica, em ordem cronológica, o ano em que os países ingressaram no Festival, utilizando cores de suas bandeiras. Para decodificar a marca, é fornecida uma versão com legenda (Figura 1). Adicionalmente, foram criadas marcas cambiantes para cada país, mostrando as particularidades da participação daquela nação no festival (Figura 2).

Figura 1: "Marca-mãe" (à esquerda) e versão legendada (à direita). Fonte: CLEVERFRANKE (2020).
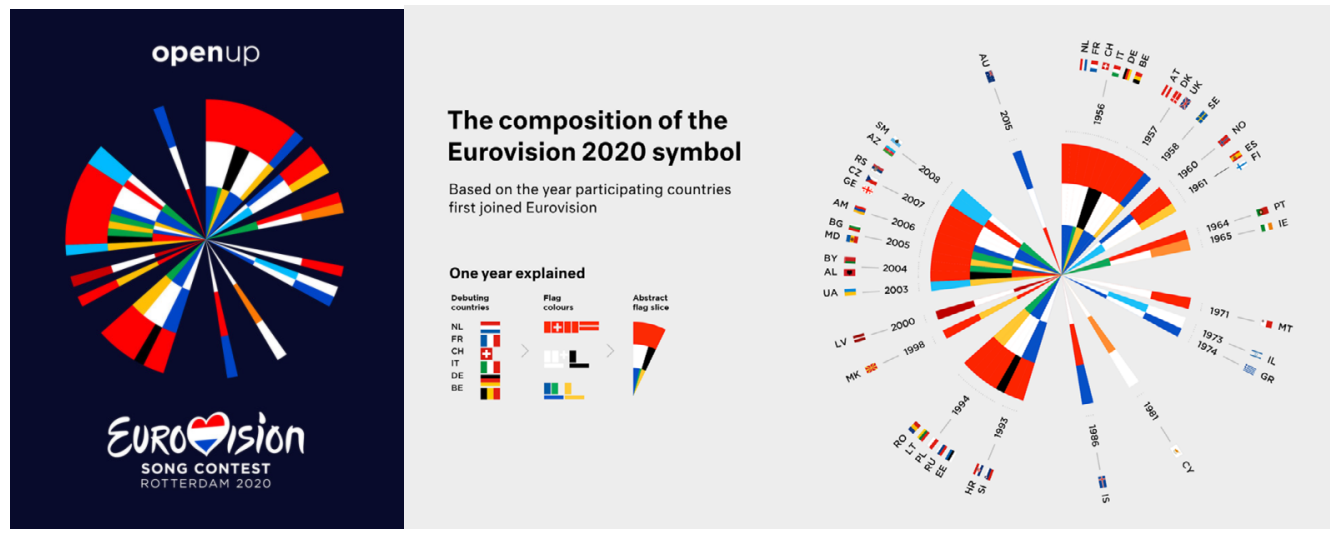

Figura 2: Marcas cambiantes para cada país integrante. Fonte: CLEVER ${ }^{\circ}$ RANKE (2020).

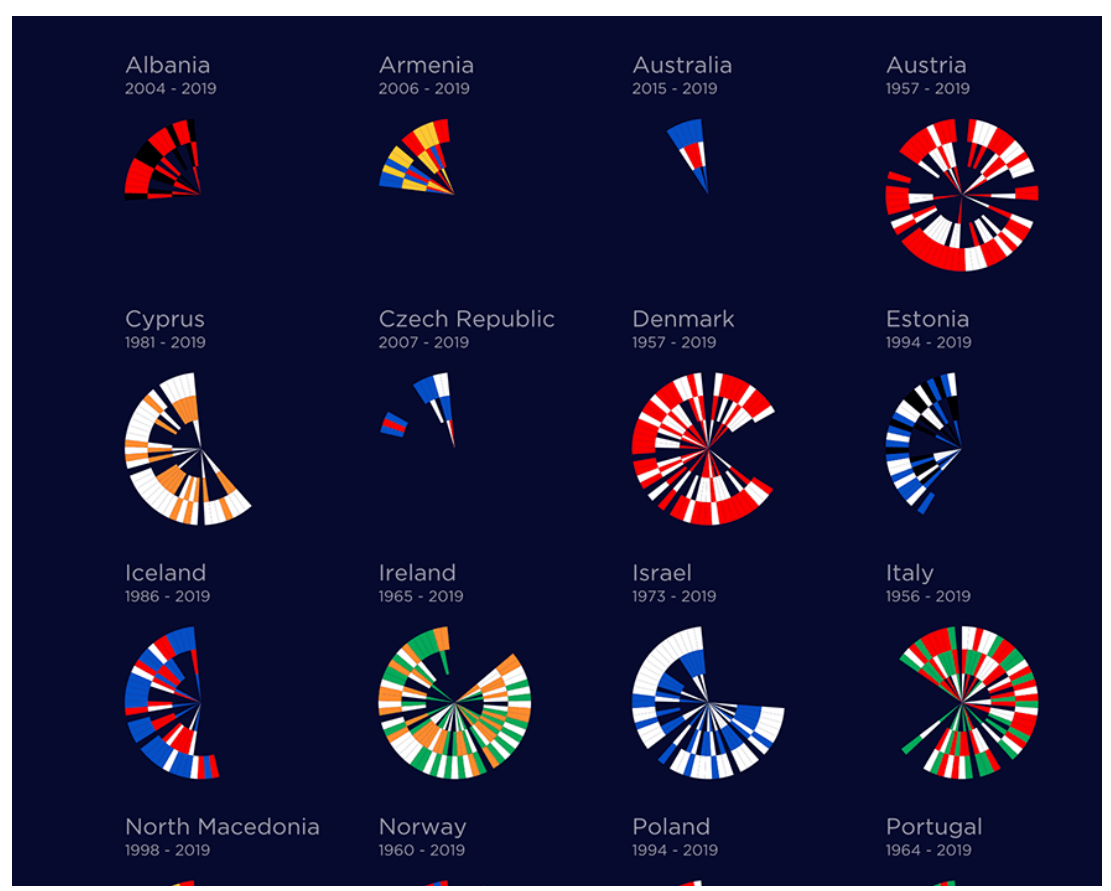

Com essa análise, destacamos a utilização de uma "marca-mãe", aplicada para casos abrangentes, e de suas variações cambiantes, utilizadas quando deseja-se referenciar um país específico. 
Nordkyn

Criado pelo Neue Design Studio (2010), a marca Nordkyn objetiva incitar o turismo na região homônima, localizada na Noruega. A marca cambiante (Figura 3) muda de acordo com as condições climáticas no local: o formato se modifica de acordo com a direção do vento e a cor varia com a temperatura, gerando novos logotipos a cada cinco minutos. A mutabilidade da forma e da cor desse logo foi uma referência importante para nosso projeto.

Figura 3: Possibilidades de variação do logotipo Nordkyn. Fonte: Neue Design (2010).

\begin{tabular}{|c|c|c|c|c|}
\hline 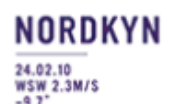 & 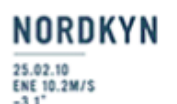 & 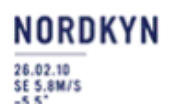 & 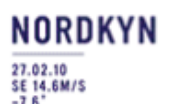 & 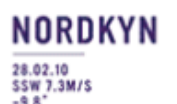 \\
\hline NORDKYN & NORDKYN & NORDKYN & NORDKYN & NORDKYN \\
\hline 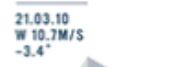 & 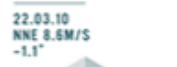 & 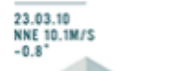 & 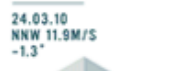 & \\
\hline NORDKYN & NORDKYN & NORDKYN & NORDKYN & NORDKYN \\
\hline 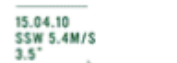 & 1804:10/5 & 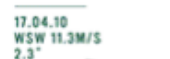 & 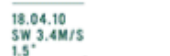 & 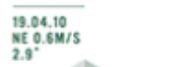 \\
\hline
\end{tabular}

\section{Execução}

Investigação e coleta dos dados

Em relação aos dados, definimos que o critério que diferenciaria os logotipos seria temporal (em intervalos anuais) pelo fato de desejarmos evidenciar a transformação do Laboratório ao longo dos anos. Assim, criamos onze variações do logotipo (de 2010 a 2020).

Após uma investigação preliminar sobre a história do LabVis, definimos outras variáveis que seriam utilizadas para a construção da marca:

- Produções: os resultados tangíveis da nossa produção, classificados em Projetos; Artigos; TCC e mestrado; e Outros;

- Pessoas: os recursos humanos, classificados em Coordenador; Graduando; Pósgraduando; e Colaborador;

- Localização: os espaços que o LabVis já ocupou, classificados em Escola de Belas Artes; Centro de Tecnologia; e Ambiente online. 
Com as variáveis definidas, conduzimos - com auxílio de planilhas - uma etapa de identificação das pessoas que já passaram pelo Laboratório e de catalogação de todos os projetos já publicados pelo LabVis, definindo autorias, taxonomia e ano de produção.

\section{Codificação visual}

Em seguida, iniciamos a etapa de codificação visual. Novas inspirações foram acrescentadas ao estudo de referências, experimentando uma gama variada de soluções. Por fim, chegamos à alternativa de trabalhar com dois gráficos de área radial (ou gráfico de radar) sobrepostos: um representando a variável Pessoas, o outro, Produções. Cada gráfico possui quatro eixos concêntricos e rotacionados em quatro ângulos congruentes.

A grid do gráfico inferior posiciona os eixos nos ângulos de $0^{\circ}, 90^{\circ}, 180^{\circ}$ e $270^{\circ}$ que definem, respectivamente, as variáveis Coordenadores, Graduandos, Pós-Graduandos e Colaboradores. Já o gráfico superior representa as variáveis Projetos, Artigos, TCCs e Mestrados e Outros - cujos eixos são posicionados nos ângulos de $45^{\circ}, 135^{\circ}, 215^{\circ}$ e $295^{\circ}$. Sobre cada eixo é posicionado um vértice cuja distância do centro representa o valor quantitativo da variável (Figura 4).

Figura 4: Estrutura da marca cambiante. Fonte: os autores.
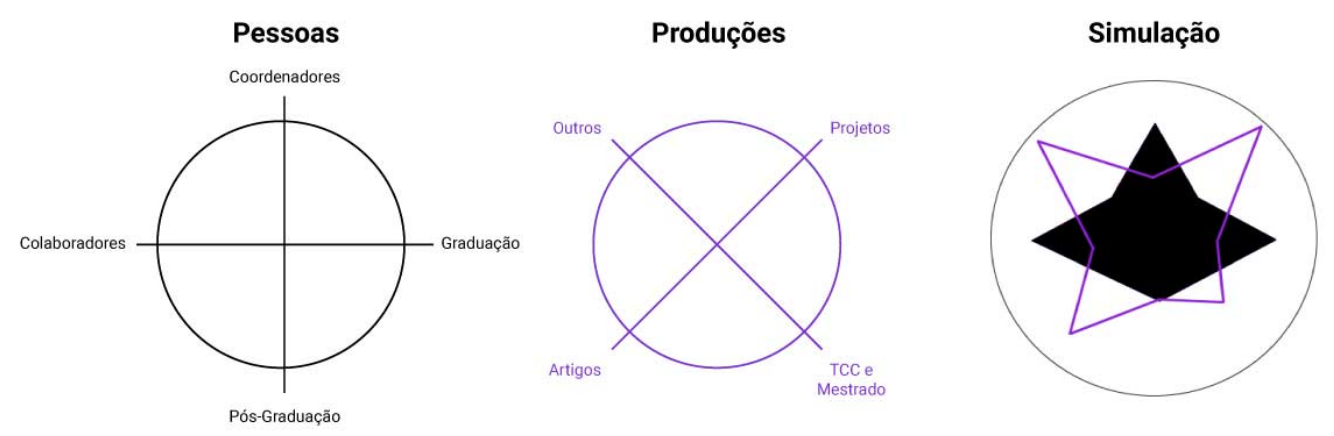

Para codificação da variável Localização, optamos pelo marcador visual de cor aplicado à área do gráfico radial inferior: rosa para o prédio da Escola de Belas Artes; azul, para o prédio Centro de Tecnologia; e amarelo para o ambiente online ${ }^{2}$. A paleta decidida teve inspiração nas cores primárias, conforme a síntese subtrativa, e também nas cores que traduzem, tanto institucionalmente quanto no imaginário da comunidade acadêmica, os centros representados.

\section{Algoritmo}

É importante ressaltar que, na criação de um logotipo generativo, o que se cria não é o logo em si, mas a forma de fazê-lo: " 'o design generativo não é sobre projetar um edifício', diz Lars Hesselgren, 'é sobre projetar o sistema que projeta um edifício' " (Stocking, 2009). Assim,

\footnotetext{
${ }^{2}$ O ambiente online representa o movimento necessário de virtualização dos espaços em decorrência da COVID-19.
} 
criamos um programa utilizando a plataforma Observable ${ }^{3}$ capaz de gerar automaticamente os logos para todos os anos, tanto os passados como os que estão por vir. A partir da inserção dos valores para cada variável, o programa cria a visualização de dados correspondente ao ano específico (Figura 5). A visualização é exportada como imagem e então transportada ao Adobe Illustrator ou outro software gráfico para ser finalizada.

Figura 5: Interface do programa que traduz os dados inseridos na marca cambiante. Fonte: os autores.

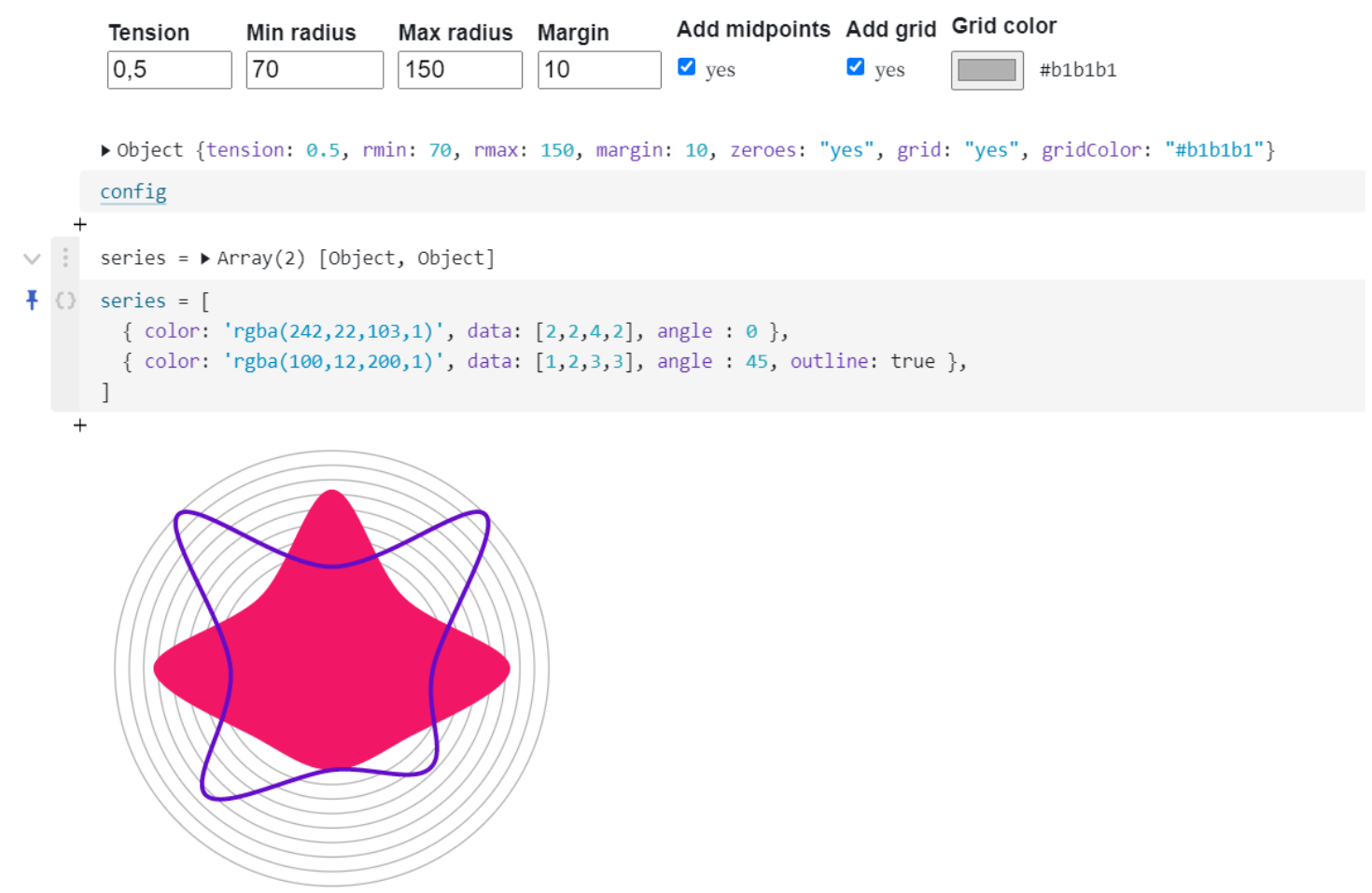

\section{Resultados}

Por meio do processo explicitado, a criação dos logotipos foi concluída. A "marca-mãe" é resultante da mistura das três cores e do posicionamento dos vértices nos pontos máximos da grid. As marcas cambiantes referentes a cada ano são resultantes da visualização dos dados daquele período em questão (Figura 6).

\footnotetext{
${ }^{3}$ Disponível em: <https://observablehq.com/d/4930b57b593eeebb>.
} 
Figura 6: Todas as marcas cambiantes da nova identidade visual do LabVis ${ }^{4}$. Fonte: os autores.
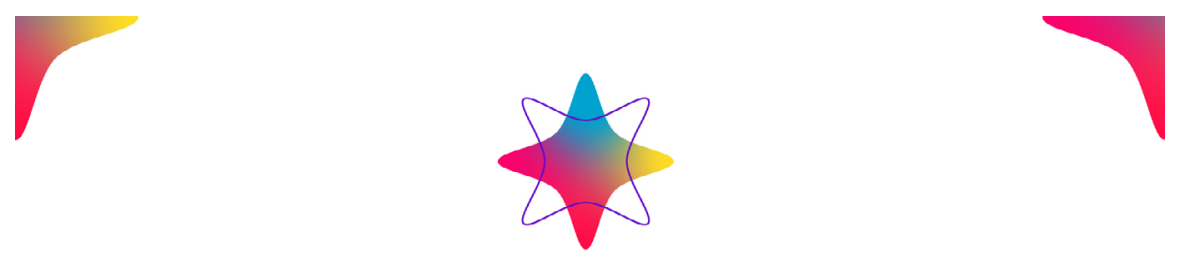

\section{$L A B$ \\ V I S}

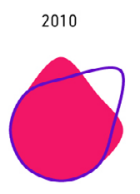

2014

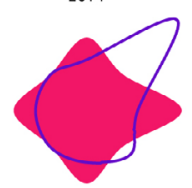

2018

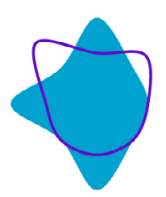

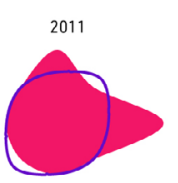

2015

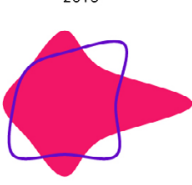

2019

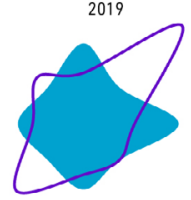

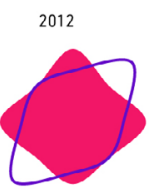

2016

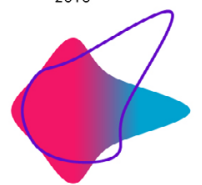

2020

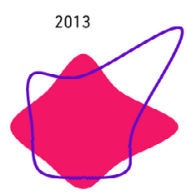

2017
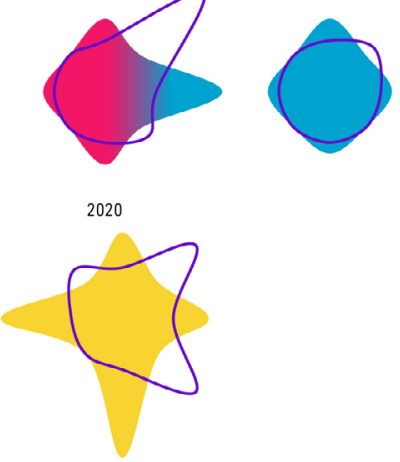

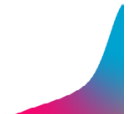

\section{Aplicação}

Com os logotipos prontos, partimos para o segundo objetivo do projeto que era o de compartilhar a nova marca cambiante com o público a partir de sua aplicação em uma série de publicações em redes sociais ${ }^{5}$.

Para criar o conteúdo das postagens, escolhemos produções que se destacaram na trajetória Laboratório. Ao todo, selecionamos 24 produções identificando seus respectivos anos de publicação e criando textos curtos para divulgá-los no formato de carrossel de posts. Cada carrossel é formado por três imagens (Figura 6):

1. a primeira consiste numa imagem representativa da produção acompanhada de seu título, autoria e manchas visuais criadas a partir da marca cambiante correspondente ao ano de produção;

2. a segunda consiste na apresentação da marca cambiante do ano em pauta acompanhada também do recurso de manchas visuais;

\footnotetext{
${ }^{4} \mathrm{O}$ ano de 2016 é excepcionalmente ilustrado com um degradê entre rosa e azul, simbolizando o incêndio no Prédio da Reitoria e a consequente transição do LabVis para o prédio do CT.

${ }^{5}$ As publicações aconteceram entre 4/12/2020 e 8/02/2021 e foram divulgadas no Instagram, Facebook e Twitter.
} 
3. a terceira explica como ler a marca cambiante, mostrando grid e legendas que tornam possível a decodificação da visualização de dados.

Figura 7: Exemplo de publicação nas redes sociais. Fonte: os autores.

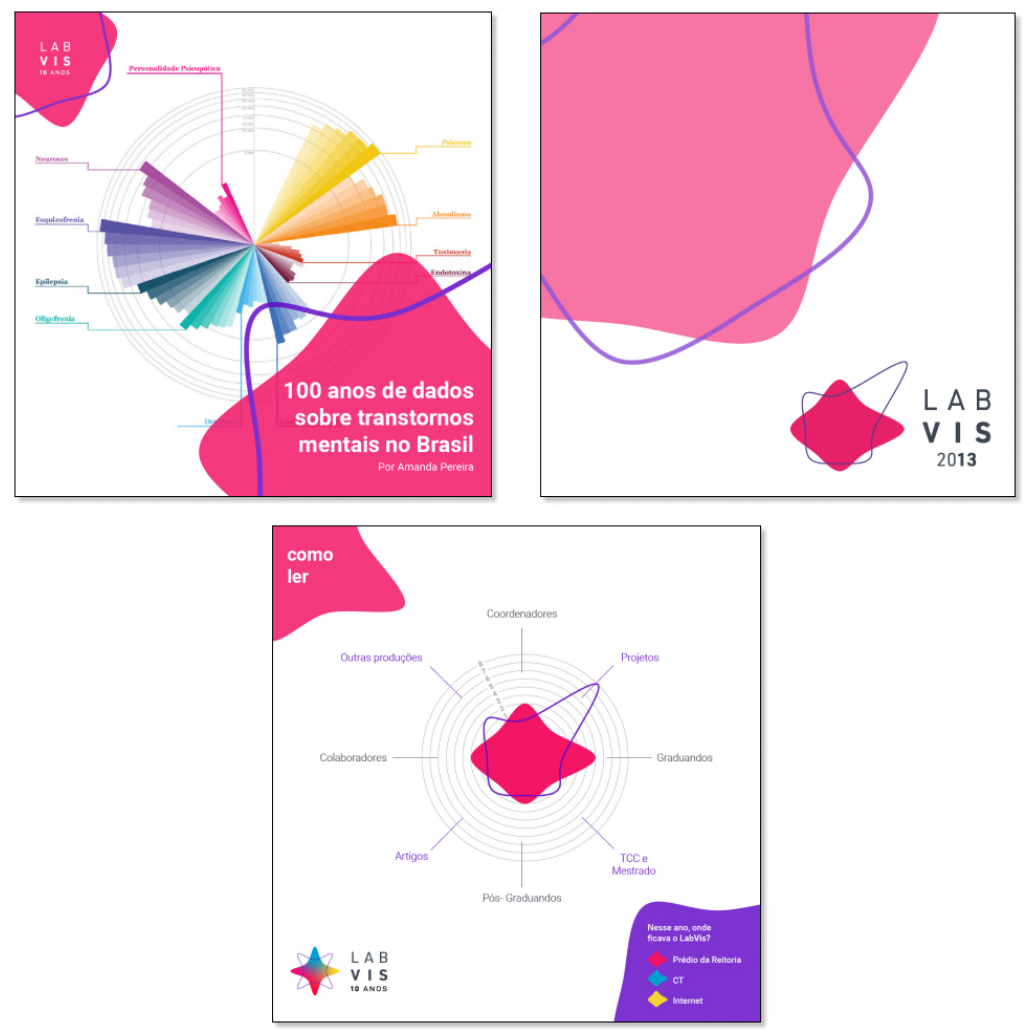

\section{Considerações finais}

A nova marca cambiante cumpriu os objetivos aos quais se propôs, contando a história do LabVis e utilizando a visualização de dados como geradora de suas diferentes formas. Por meio dela, foi possível criar uma retrospectiva que deu visibilidade às atividades de pesquisa do Laboratório.

Apesar da pluralidade de combinações possíveis, a marca cambiante mantém sua unidade e pregnância por meio da sistematização de um dicionário visual. Assim, criamos uma marca que reflete a história e área de estudo do LabVis e é, ao mesmo tempo, memorável, consistente e flexível.

Finalmente, a marca cambiante alia ferramentas de computação aos princípios do design da informação para representar e comunicar dados. Dessa forma, buscamos evidenciar que a visualização de dados está longe de se restringir a produção de gráficos tradicionais e aplicações objetivas (e.g. informar e apoiar melhores decisões), podendo se estender a outras possibilidades de uso como a comunicação visual de marcas e a contação de histórias. São inúmeras as potencialidades existentes no âmbito da visualização de dados e o LabVis busca explorá-las e expandi-las. 


\section{Referências}

Card, S., Mackinlay, J., \& Shneiderman, B. (2007). Readings in information visualization. San Francisco, Calif.: Morgan Kaufmann.

CLEVER ${ }^{\circ}$ FRANKE. (2020). Recuperado em 30 abril 2021, de https://www.cleverfranke.com/work/eurovision

Kopp, R. (2002). Design gráfico cambiante. Brasil: Pontificia Universidade Católica do Rio Grande do Sul. Faculdade de Comunicação Social.

Sociedade Brasileira de Design da Informação (SBDI). (2020). Definições. Recuperado em 30 abril 2021, de http://www.sbdi.org.br/definicoes.

Souza, E. A. R. (2013). Design gráfico cambiante na identidade visual do Festival UFC de Cultura (2009-2012). Trabalho de conclusão de curso, Universidade Federal do Ceará, Instituto de Cultura e Arte, Departamento de Comunicação Social, Curso de Comunicação Social, Fortaleza, Brasil.

Stocking, A. (2009). Generative Design Is Changing the Face of Architecture | Cadalyst. Recuperado em 30 abril 2021, de https://www.cadalyst.com/cad/building-design/generativedesign-is-changing-face-architecture-12948

Van Ness, I. (2012). Dynamic Identities: How to create a living brand. Amsterdam: Bis Publishers.

Visit Nordkyn. (2010). Recuperado em 30 abril 2021, de https://neue.no/work/visit-nordkyn/.

\section{Sobre os autores}

Julia Ebel Lopes, estudante de graduação, UFRJ, Brasil <jubelopes@hotmail.com> Júlia Giannella, Dra., UFRJ, Brasil <juliagiannella@gmail.com>

Doris Kosminsky, Dra., UFRJ, Brasil <doriskos@eba.ufrj.br>

Claudio Esperança, Dr., UFRJ, Brasil <esperanc@cos.ufrj.br> 